\title{
To Evaluate Cost Savings in a Supply Chain : Two Examples from Ericsson in the Telecom Industry
}

\author{
Annelie I. Pettersson \\ Industrial Logistics, Luleå University of Technology, SE-971 87 Luleå, Sweden \\ Ericsson AB, SE-16422 Kista, Sweden \\ Email: annelie.pettersson @1tu.se (Corresponding Author) \\ Anders Segerstedt \\ Industrial Logistics, Luleå University of Technology, SE-971 87 Luleå, Sweden \\ Email: anders.segerstedt @ltu.se
}

\begin{abstract}
An accurate cost analysis is necessary to evaluate changes in a supply chain; this article shows how a rather simple framework can be used when evaluating changes in a supply chain. The framework is built on a Supply Chain Cost (SCC) model and customer service measurements, delivery precision and leadtime. Both suggested changes in a supply chain and already executed changes can be evaluated by the framework. Two different examples from the company Ericsson are presented to illustrate the framework, which is a 5 step analysis model. The existing, or pre-existing, supply chain is analysed, described and defined. The SCC and performance measures are measured and/or estimated. Improvements are designed and defined. The same measures as before are measured again. The measures from before and after the change of the supply chain are evaluated to decide if the changes are improvements or not. Cutting costs in one area of the supply chain can be a mistake if not the total supply chain is considered and the total SCC. Considering both the SCC part and customer service measures present a wider understanding of the change. It is shown that SCC can be used as a tool to identify cost savings and evaluate if a change project will, or has, resulted in the cost savings the project aims for. Rough standard costs measures should be avoided instead actual costs should be used as much as possible. The used framework hopefully stimulate to similar analyses in other companies with other supply chains.
\end{abstract}

Keywords: Supply Chain Management, performance measurements, supply chain cost, supply chain excellence

\section{INTRODUCTION}

There is high pressure on companies to increase profit and at the same time the customers are demanding lower prices; therefore the companies have to cut cost in all areas. According to Tummala et al. (2006) making changes to the supply chain helps to lower cost and enables a company to more easily compete based on the price. Kumar and Chang (2007) highlight that cutting cost in a company increase net income. The performance of a supply chain decides the company's success according to Lahti et al. (2009). Shahabuddin (2011) found in his study that companies that adopted supply chain processes were more profitable that those that did not.

Evaluating changes in a supply chain can be difficult. Have the changes in the supply chain led to the reduced costs and improved customer service as it intended to do? To be able to answer this question you need some approach to evaluate the result from cost and customer service aspects. New (1996) claimed that is difficult to quantify the expected economic consequences of improved Supply Chain Management (SCM). This paper is concerned with Supply Chain Cost (SCC) and how this measure with its components can be used to identify and evaluate improvements of the supply chain. The paper describes two studies performed at Ericsson AB during 2011. The aim with the presented studies is to show that a framework built on SCC measurement combined with customer service measures can be used to evaluate changes that have been done but also changes that are planned to be executed.

\section{SUPPLY CHAIN MANAGEMENT AND SUPPLY CHAIN COST}

Supply Chain Management (SCM) has received a considerable amount of interest both from researchers and in the industry. The SCM concept came up just before the 1960s according to Huan et al. (2004). The study of SCM increased in the 1980s and had a dramatic increase in the 1990s (cf. Huan et al. (2004)). More and more companies have to focus on their supply chain in order to be successful in their business. Already in 1997 top managers had recognized the importance of having effective Supply chains to create competitive advantage according to Higginson and Alam (1997) and Cooper et al. (1997). Supply chain management is one of the key activities that give the success of a company, Cambra and Polo (2008). Spens and Wisner (2009) state that SCM is still viewed as very worthwhile.

There are many definitions of SCM in the literature. The definitions focus on different things. There is cost focus, customer service and inventory cost focus and the flow focus. Shapiro (2001) writes that the traditional objective of SCM is to minimize the total Supply Chain Cost to meet 
fixed and given demand. This total cost may include the following:

- Raw material and other acquisition costs.

- Inbound transportation cost

- Facility investment costs

- Direct and indirect manufacturing cost.

- Direct and indirect distribution cost

- Inventory holding cost

- Interfacility transportation cost

- Outbound transportation cost

Christopher (1998) defines SCM as the management of upstream and downstream relationships with suppliers and customers to deliver superior customer value at less cost to the Supply chain as a whole. Johnston (1995) defines SCM as the process of strategically managing the movement and storage of materials, parts and finished inventory from suppliers through the firm to customers. Kranz (1996) defines SCM as the effort involved in producing and delivering a final product from a supplier's supplier to the customer's customer. Carter et al. (1995) define SCM as a co-ordinated approach for managing the flow of goods from suppliers to ultimate customers, and that the goal is to meet customer service objectives while minimising inventory and related costs. Simchi-Levy (2000) says that "Supply Chain Management is a set of approaches utilized to efficiently integrate suppliers, manufactures, warehouses and stores, so that merchandise is produced and distributed at the right quantities, to the right locations, and at the right time, in order to minimize system wide costs while satisfying service level requirements"

Supply Chain Management is described by Ellram (1990) as the integration of control and planning of materials and product flow from supplier to customer. Simchi-Levy (2000) defines Supply Chain Management as " a set of approaches utilized to efficiently integrate suppliers, manufactures, warehouses, and stores, so that merchandise is produced and distributed at the right quantities, to the right locations, and at the right time, in order to minimize system wide costs while satisfying service level requirements."

The objective of Supply Chain Management (SCM) is to improve operations management across functional boundaries in the supply chain. Therefore one purpose of $\mathrm{SCM}$ is to reduce the supply chain's total costs and improving the quality and service to its end customers (Berry and Naim, 1996). Cambra and Polo (2008) mean that SCM is one of the key activities that present the success of a company. Also the design and management of its supply chain is an important factor for the success of any company (MacFarland et al., 2008). It is difficult to quantify the expected economic consequences of improved SCM (New, 1996). To claim that a company has become more efficient after an optimisation work that has been performed without being able to evaluate the economic consequences is risky. Therefore it is valuable for a company to have methods for cost evaluations. In order for a company to accomplish cost evaluations the focus shall be on the total supply chain to acquire the total picture. According to Collin et al. (2009) is it important to consider all the existing flows in the supply chain, from the origin to the final customer. Customer satisfaction and service should be the leading goal for supply chain managers and cost reduction is the prime focus (Fawcett et al, 2008). All supply chains of the future will likely focus their efforts on achieving success through process improvement and collaboration on strategic, tactical, and operational levels (Beamon, 1998).

The system for performance measurements in a company is an important factor for excellent management of a supply chain. The lack of standardized metrics and inappropriate Enterprise Resource Planning (ERP) functionality could be obstacles for performance measurements integration, (Forslund and Jonsson, 2007). The importance of supply chain performance measurement is increasing at a time when supply chain networks have become more complex (Mondragon and Lalwani, 2011). de Waal and Counet (2009) say when implementing performance measurement systems companies the most severe problems are lack of top management commitment and not having a performance measurement culture. The lack of awareness about performance measurement systems in supply chains are a significant barrier for implementing systems for performance measurements (Charan et al., 2009). Forslund (2010) point out that the future for performance measurement seems bright due to that the ERP systems have developed fast during the years.

Supply Chain Cost is defined as all relevant costs in the supply chain of the company, or organisation, in question. Analysis of SCC can be performed in different ways. Different kind of grouping of cost can be found in the literature. Bowersox and Closs (1996), Chen (1997), Sachan et al. (2005) and Byrne and Heavey (2006) have done similar definitions. These definitions use for example different terms for the same thing like Production cost in the definition of Chen (1997) and Manufacturing cost in the Bowersox and Closs (1996) definition. Chen (1997) says that SCC can be placed in the five categories: Production cost, Transportation cost, Warehousing cost, Inventory carrying cost and internal material handling cost.

Many companies limit their definition of cost only to those costs that are contained within the four walls of their business entity (Christopher and Gattorna, (2004). Svensson (2010) questions if companies learn from previous failures, he even wonders whether companies ever learn from previous mistakes. Using SCC to evaluate cost savings and improvements in a supply chain can help companies to learn from previous changes in the supply chain and avoid the same mistakes in future change projects. The main obstacle to supply chain excellence in a company is the behaviour of people according to Halldorsson et al. (2008). The supply chain requires active management to maximize efficiency and effectiveness (Canever et al., 2008; Walters, 2008). Hayashi et al. (2009) have found that the sales function and the production function do not always work together for profit optimization. In most cases, the sales function is responsible for maximizing sales. On the other hand, the production function is responsible for minimizing production cost

There is a need to take a supply chain view of costs. For many companies many of their costs lie outside their own legal boundaries. Production and distribution activities that used to be performed in-house are now often out sourced to 
specialist service providers. Total SCC includes both cost coming from the own company, but also cost for services bought from an external company. Measuring the total SCC presents information that helps the company to evaluate if the design of its supply chain is competitive or if it should be redesign. Accurate SCC provides a company a base for learning about different supply scenarios. Accurate SCC measurements help managers of the supply chain to take correct decisions. Finding all cost parts within SCC can be difficult for some companies and some companies are using allocations for indirect cost Hatzis et al. (2011) claim that the most significant problems that the companies indicated regarding the costing procedure were the incorrect allocation of indirect costs to the provided services and the problem of the acquisition of right costing information.
There is no general definition of SCM and SCC. In general, all definitions claim that SCM is a management philosophy, which has both intercompany and outer company scope. It includes all activities from the raw materials stage through to the end-user with the focus on optimization and efficiency (Tan et al., 2002). A lot of attempts to define logistic costs and SCC exists (Pettersson and Segerstedt, 2013).

This paper uses the suggestions and definitions of Pettersson and Segerstedt (2012, 2013). In this definition SCC is divided into 6 main categories: Manufacturing cost, Administration cost, Warehouse cost, Distribution cost, Capital cost and Installation cost. Every category is in its turn subdivided in different cost elements, see Figure 1.

\begin{tabular}{|l|}
\hline $\begin{array}{l}\text { Supply Chain } \\
\text { Cost }\end{array}$ \\
\hline
\end{tabular}

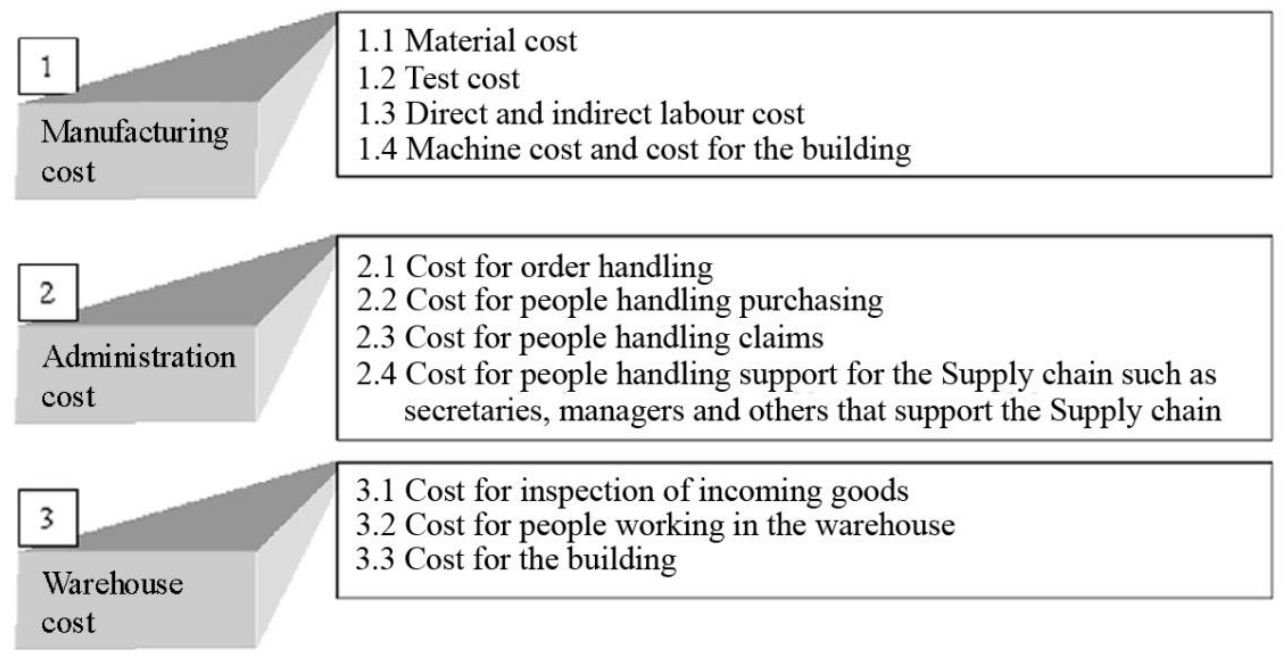

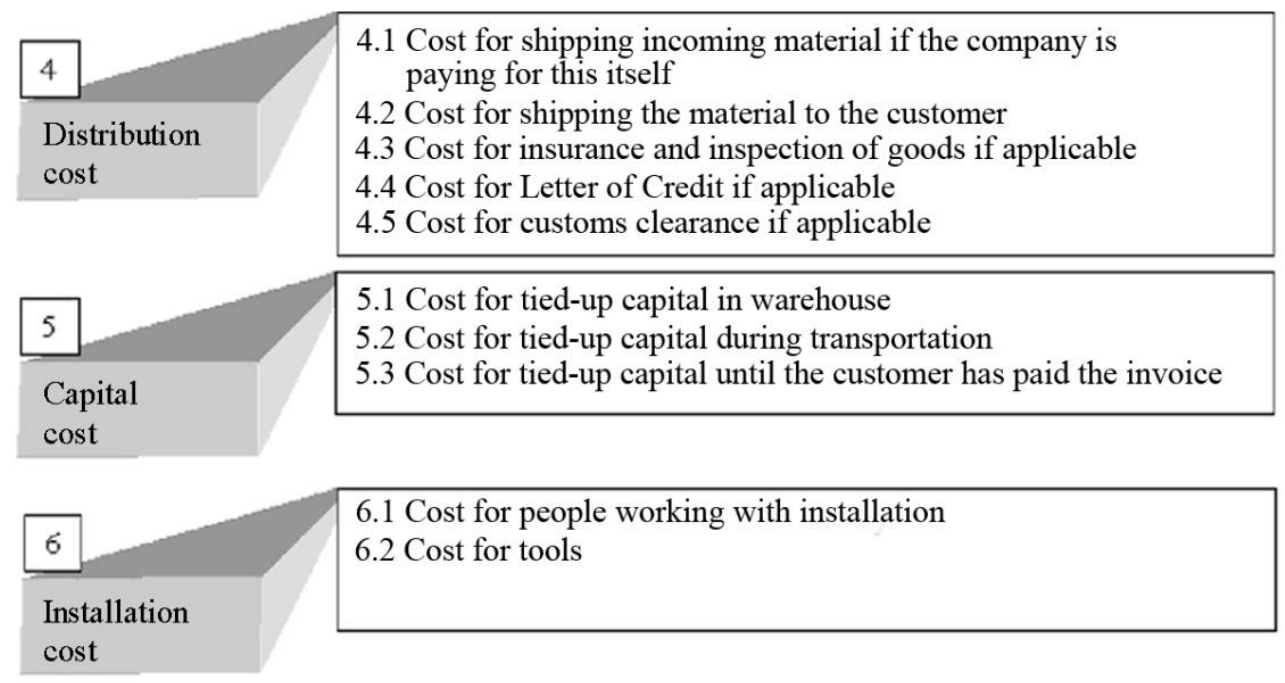

Figure 1. Contents for Supply Chain Cost (source: Pettersson and Segerstedt (2013))

The SCOR model, developed and maintained by the Supply Chain Council, is known in many companies. The
SCOR model uses some different designations; Cost of goods sold and Supply Chain Management cost (SCOR handbook version 8). The SCOR model is a reference model that can be used to map, benchmark, and improve supply 
chain operations. SCOR provides companies with a basic process tool for modelling, a database for benchmark, and defines a set of metrics for the supply chain. Cost of goods sold is the cost associated with buying raw materials and producing finished goods. This cost includes both direct costs (materials, labour) and indirect costs (overhead). Total Supply Chain Management Cost denotes the fixed and operational costs associated with the Plan, Source, Make, and Deliver Supply chain processes. The costs included are order management (Deliver), material acquisition (Source), inventory carrying (Indirect Plan), planning/finance (Plan), and information technology costs (Indirect Enable). The Supply Chain Management costs in the SCOR model covers most of the SCC model described in Pettersson and Segerstedt (2013) and Figure 1. The differences between the two models are the terms used for the different cost elements and partially the measurement level. Order management cost in the SCOR model is included in the Administration cost in the Pettersson and Segerstedt (2013) model. The measurements in the SCOR model are recommended to be performed on a quite detailed level; therefore the SCOR model can be experienced as complicated due to the detailed measurement level.

The variation of definitions and terms is not an obstacle for a company to work with SCC. The most important for a company is to define the cost elements that are included in the SCC and then use the terms consequently. SCC in this study is defined as the cost in the companies' whole supply chain from raw material stage until the finished product is delivered to the customer.

\section{STUDY EXAMPLES FROM ERICSSON AB}

\subsection{Introduction to Ericsson $A B$}

Ericsson is a world-leading provider of telecommunications equipment and related services to mobile and fixed network operators all over the world. The company has customers in more than 175 countries according to Ericsson (2012). More than 40 percentages of the world's mobile traffic passes through Ericsson's networks. The Ericsson organization has four Business Units: Business Unit Networks; Business Unit Global Services; Business Unit Multimedia; Business Unit CDMA Mobile Systems

Research, Regions, and Group are the other parts of the organization. Each Business has a Supply unit. This unit is taking care of all Supply related issues. Each Region also has a supply unit.

Ericsson has a wide scope of products: Mobile systems, Wireline systems, Transmission and transport, Service layer and Services

\subsection{Study Approach}

Kähkönen (2011) argues that case studies are suitable research of supply chain management. However, according to e.g. Yin (2003) and Kähkönen (2011) our study may not be classified as a proper case study. It only presents short descriptions of two analyses and evaluations of changes in different supply chains at Ericsson. The analysis and evaluation was performed by a group of people all employed by Ericsson. One of the participants in the group was the main author of this article. Ericsson has many competitors therefore Ericsson is restrictive to make public their successes, and failures, especially when it comes to the design of their supply chains and processes. The design of their supply chains and processes are the core business; it decides profit and/or loss. This restricts the scope of this presentation. However the aim with this article is not to present a close case study, but the main idea with the article is to illustrate a framework or model for evaluating changes in a supply chain. The Supply Chain Cost (SCC) in the two examples is measured according to the model and definition in Pettersson and Segerstedt (2013) and Figure 1. The two scenario analyses are based on a five step approach measuring SCC and customer service measures, delivery precision and lead-time, before and after a performed or planned change. Before means that SCC is measured in the supply chain as it is designed before the change. After means that SCC is measured after the change in the supply chain. The first step in this evaluation model is to define the supply chain that will be studied. Next step is to measure SCC and customer service measures in the defined supply chain. The third step is to define improvements or define changes that have been done. In the fourth step the SCC and customer service measures are measured again and in a fifth step the measurements from step 2 and step 4 are compared and analysed. The definition of the analysed supply chains was performed in a group of colleagues within the supply organisation at Ericsson. Costs elements to the SCC measurements were collected from Ericsson's Enterprise Resource Planning (ERP) computer system.

\subsection{Example 1: Direct deliveries to customers}

This study is performed on a supply chain Ericsson is in control of and responsible for. Some parts in the supply chain are within Ericsson boundaries and some parts are bought as a service from companies outside Ericsson. The idea with the study is to find improvements that both present better customer service and decreased costs through a substantial change of the distribution link from production to end customers.

The evaluation framework with 5 steps presented in section 2.2 is applied to Example 1 together with service measurements. Both SCC and service measurements are important factors when evaluating the excellence in a supply chain (Pettersson and Segerstedt, 2012). Customer service includes delivery precision and lead-time. Delivery precision is calculated as the number of orders delivered in time compared to the total number of orders delivered during a month. In time means on confirmed delivery date, the exact promised day. The lead-time, or delivery time, is the time from receiving customer order until the order is delivered to customers place. The studied supply chain is a chain from customer ordering a product until the product is delivered to the customer. Each involved step in the process creates and adds cost to the total SCC. 
Step 1: Analyse, describe and define version one of the supply chain

The first step is to define and analyse the supply chain in this case in control of Ericsson. The first thing that is happening in this supply chain is that customers are sending orders to the local company $(L C)$ in the country where the customer is located. Thereafter is the order sent to an Order desk that takes care of all customer orders. The Order desk sends a purchase order to an external production facility. The produced material is sent to a delivery centre in another country, marked with $E S D / E D C$ in Figure 2. After that the ordered material is sent to a local warehouse in the country where the customer is situated. The last step in the supply chain is from the local warehouse to the customer warehouse, marked with Cust. WH, Site in Figure 2.

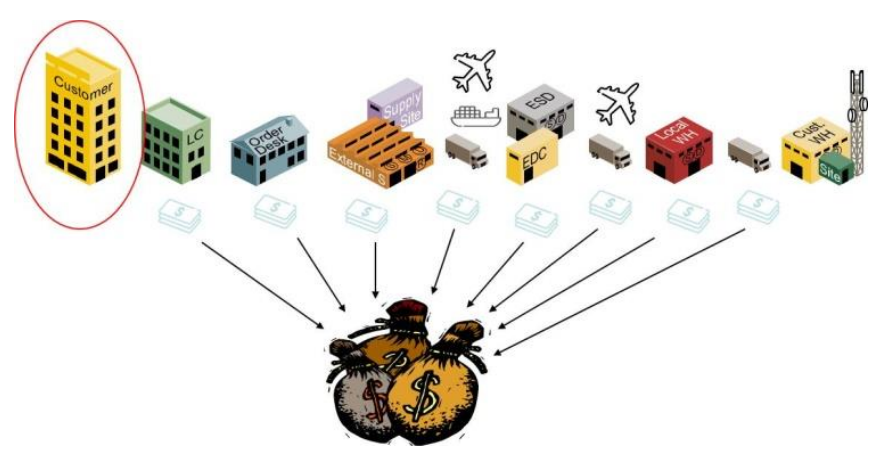

Figure 2. Example 1: Original flow, supply chain, creating costs

Step 2: Measure SCC and customer service measures for version one

Manufacturing cost is created and added at the External Supplier, marked with External $S$ in Figure 2. Administration cost is added at the $L C$ and the Order desk. Distribution cost is added when transporting material from External Supplier to $E S D / E D C$, from ESD, EDC to Local warehouse and from Local warehouse to Customer Warehouse. Capital cost is added when the external supplier is paid for their manufacturing work until the customer has paid for the delivered material. Warehouse cost is added for $E S D / E D C$ and Local Warehouse. The Customer warehouse is paid by the customer and therefore not included in Ericsson's SCC. Manufacturing cost and Distribution cost comes from external suppliers in the supply chain. The costs are the amount of money Ericsson pays to the supplier handling the production and to the supplier handling the distribution. The prices are negotiated on annual basis for each product and each distribution route.

SCC in the defined Supply chain is measured by the Controller in the supply chain monthly. Here is the measurement presented in distorted "money units" (MU). But the MU shows the correct differentiate between the different costs.

Total SCC measured before changes in the supply chain were initiated:
SCC

\begin{tabular}{ll}
\hline Manufacturing cost & 5.1 \\
Administration cost & 1.5 \\
Warehouse cost & 0.4 \\
Distribution cost & 0.8 \\
Capital cost & 0.4 \\
\hline Total SCC & 9.2
\end{tabular}

Delivery precision: 95\%; Lead-time: 16 days

Delivery precision and lead-time is measured based on figures from the ERP system. How delivery precision and lead-time are measured was mentioned above.

\section{Step 3: Design and define suggested improvements from} version one

In this case a group of supply chain managers at Ericsson started a project with the purpose to reduce cost while maintaining or improving the level of delivery precision and lead-time. The group agreed to the following improvement: Ship direct from the external supplier to the customer.

By implementing the suggested improvement the group believed that the total SCC should decrease and that the lead-time should be decreased. The reason for that was that transportation between warehouses in different countries was removed. By that they expected that the distribution and the warehouse cost should be reduced. The new supply chain is presented in Figure 3 with marks where SCC comes from. Manufacturing cost is added at External supplier, marked with External $S$ in Figure 3. Administration cost is added at $L C$ and Order Desk. Distribution cost is added when transporting material from External Supplier to Customer Warehouse. Capital cost is added when the external supplier is paid for their manufacturing work until the customer has paid for the delivered material.

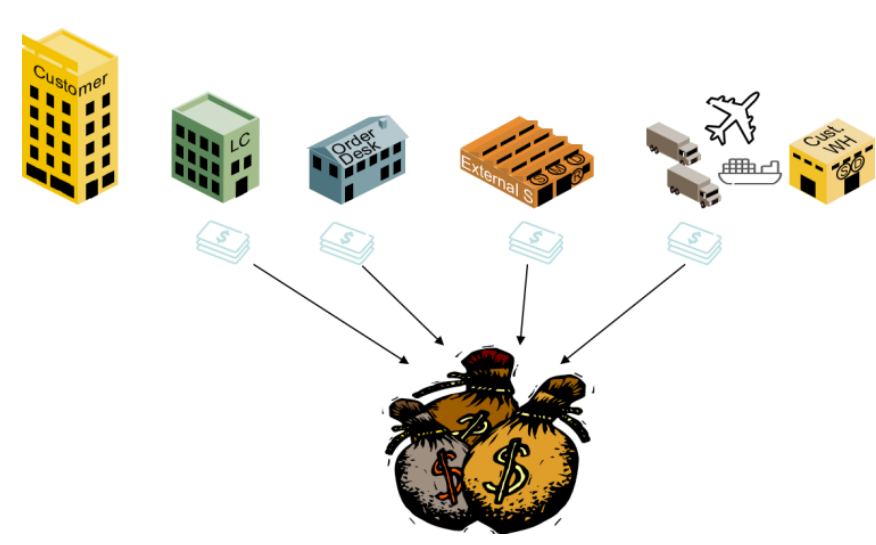

Figure 3. Example 1: New distribution channel 
Step 4: Measure SCC customer service measures for version two of the supply chain

Total SCC measured the month after changes in the supply chain were implemented :

SCC

\begin{tabular}{lc} 
Manufacturing cost & 5.1 \\
Administration cost & 1.3 \\
Warehouse cost & 0 \\
Distribution cost & 0.2 \\
Capital cost & 0.3 \\
\hline Total SCC & 7.1
\end{tabular}

Delivery precision: $98 \%$; Lead-time: 8 days

The cost parts, delivery precision and lead-time are measured according to was mentioned above. The cost measurements come from the financial measurements in the company and are based on reports from the ERP system Ericsson is using. Measurements of delivery precision and lead-time come from the ERP system and are measured every month.

\section{Step 5: Compare and evaluate the different versions}

The total SCC was reduced by $2.1 \mathrm{MU}(23 \%)$. Delivery precision was increased by 3 percentages and the lead-time was reduced by 8 days. To ship direct from the external supplier to the customer is in this case a favourable change. It is important in an analysis to evaluate both total cost changes and measures treating customer satisfaction.

\subsection{Example 2: Move of production to low- wage countries}

The second example treats another supply chain also controlled by Ericsson. The studied supply chain had recently been changed at Ericsson. The reason for the change was to reduce costs, especially manufacturing costs, and at the same time keep the same grade of service to customers. Changes that have been done are that the production facilities have been moved from England to China and Mexico. The study is performed to evaluate if the change has resulted in the cost savings the company was aiming for.

Step 1: Analyse, describe and define version one of the supply chain

The supply chain is described as it looks like before the change was implemented. Customers are sending orders to the local company in the country the customer are located. Thereafter is the order sent to the order desk. The order desk sends a purchase order to an external production facility. The produced material is sent to a delivery centre in another country. After that the ordered material is sent to a local a warehouse in the country where the customer is situated. The last step in the supply chain is from the local warehouse to the customer, see Figure 4.

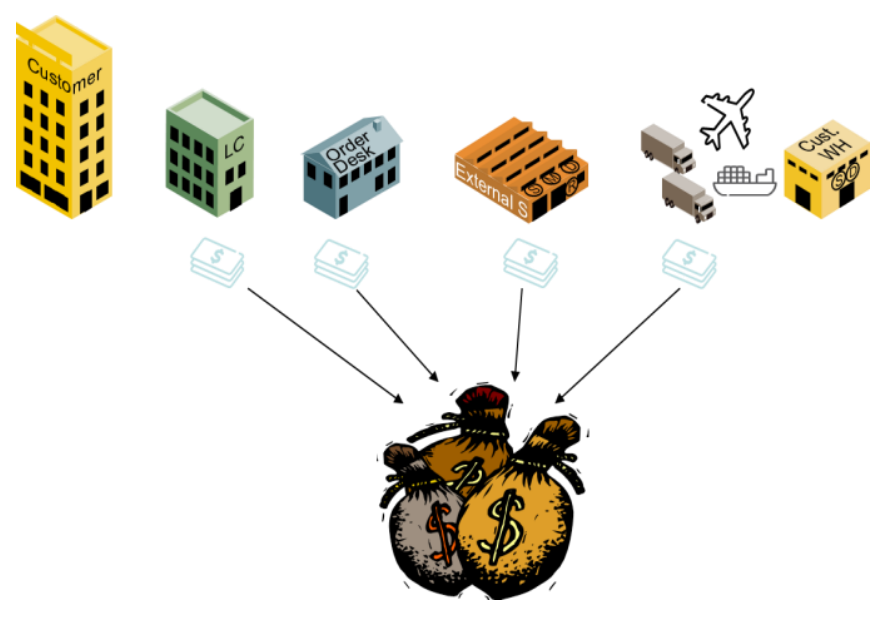

Figure 4. Example 2: Original flow creating costs

Step 2: Measure SCC and customer service measures for version one

Both costs and customer service measures, delivery precision and lead-time, were measured during the period of time the changes in the supply chain were implemented. Therefore both total SCC and performance towards the customers before and after the change can be measured. All measurements are measured in the same way as described in Example 1.

Total SCC measured the month after changes in the supply chain were implemented :

\begin{tabular}{lc} 
SCC & (MU) \\
\hline Manufacturing cost & 8.2 \\
Administration cost & 1.3 \\
Warehouse cost & 0.3 \\
Distribution cost & 0.9 \\
Capital cost & 0.3 \\
\hline Total SCC & 11.0
\end{tabular}

Delivery precision: $97 \%$; Lead-time: 12 days

Delivery precision and lead-time is measured based on figures from the ERP system.

Step 3: Design and define suggested improvements from version one

The supply chain manager of the supply chain decided to move the production from Europe to Latin America and Asia to decrease the production cost. By implementing the suggested improvement the supply chain manager believed that the total SCC should decrease and that the lead-time and delivery precision could remain unchanged. Due to the change from one production facility to two facilities on different continents two different delivery centres have to be used, see Figure 5. 


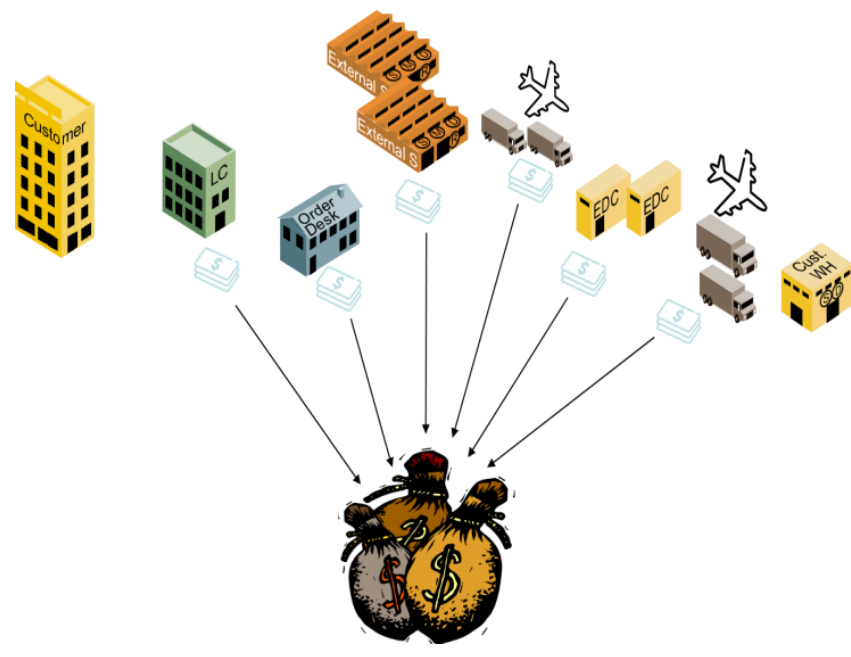

Figure 5. Example 2: The new flow, supply chain

Step 4: Measure SCC and performance towards the customers for version two of the supply chain

Total SCC measured the month after changes in the supply chain were implemented :

\begin{tabular}{lc} 
SCC & $(\mathrm{MU})$ \\
\hline Manufacturing cost & 7.9 \\
Administration cost & 1.4 \\
Warehouse cost & 0.4 \\
Distribution cost & 1.1 \\
Capital cost & 0.4 \\
\hline Total SCC & 11.2
\end{tabular}

Delivery precision: $93 \%$; Lead-time: 15 days

Delivery precision and lead-time is measured based on figures from the ERP system.

\section{Step 5: Compare and evaluate the different versions}

Using this five step model revealed outcome of the change. The assumed cost saving turned out to be an increase in total cost. The production cost was decreased, but cost for administration, warehouse, distribution and capital increased. The total SCC did not decrease; it increased from $11 \mathrm{MU}$ to $11.2 \mathrm{MU}$. The customer satisfaction was expected to stay on the same level as before the change, but the lead-time increased and the delivery precision decreased. A conclusion drawn from this example is that it is risky to take decisions based on assumptions. The idea about cost saving in this example was based on reduced production cost. The calculation of the Total SCC showed another result. Another conclusion is to consider the total SCC and not only parts of the cost to catch correct information of the situation.

The calculation of costs in both examples presented here are as far as possible based on actual costs. None of the calculations are based only on standard cost. This is also important for the reliability of the measurement.
Calculations based on rough standard cost measures may present a different picture of the situation (Pettersson and Segerstedt, 2013).

\section{CONCLUSIONS}

A rather simple analysis model based on SCC measurement and customer service measures is presented in this paper. The five step model is applied to two real examples at Ericsson. The first example shows how the framework can be used to identify cost savings in a change of the distribution flow; more direct deliveries to end customer. The second example shows how the framework can be used to evaluate a move of production to low-cost countries. But the cases do not present any general information about the consequences of moving production to low-cost countries or changes of the distribution link; the aim is to show the use of the framework.

The supply chains differ between companies and also within the company. The two examples present ideas to analyse similar problems in other companies. The five step model can be used in most types of supply chains. It is important to identify and define the supply chain that will be analysed. To get the most reliable facts actual cost should be used as much as possible instead of standard cost.

Cutting costs in one area of the supply chain can be unsuccessful if not the consequences for the total supply chain is considered. The company might think that the total SCC in the company is reduced when the distribution cost has decreased, but the effect can be the opposite. Measuring the total Supply Chain Cost might show a reduced distribution cost, but higher capital cost and production cost. This gives a negative impact on the company. Therefore it is very important to have a total view on the Supply Chain Cost when working with reducing cost in the supply chain.

Some cost elements in SCC may be decided not to be included if the elements are seen as not relevant in the study. In some companies the responsibility for the supply chain can be divided by many different departments within the company. Therefore it could be sufficient to exclude parts of the supply chain and also some SCC elements. For example can Manufacturing cost be excluded in a study where the production part is out of scope for the project that should work with cost savings or evaluating different changes only considering the distribution from production to end customer.

This supply chain analysis framework can also be used for comparing different alternatives. A company can for example identify two different alternatives to design their supply chain. To be able to decide which alternative is the best the company can use this suggested steps to measure and evaluate SCC for the two, or several, alternatives. It is important to combine the SCC measurement with factors that affect the customer satisfaction like for example leadtime to customer and delivery precision. A company with low SCC, but having discontented customers is not in a desired position if they lose customers due to low performance. 


\section{REFERENCES}

Beamon, B. M. (2008), Sustainability and the future of Supply Chain Management, Operations \& Supply Chain Management, 1 (1), pp. 4-18.

Berry, D. and Naim, M.M. (1996), Quantifying the relative improvements of redesign strategies in a PC supply chain, International Journal of Production Economics, 46-47 (1), pp. 181-196.

Bowersox, D. J. and Closs, D. J. (1996). Logistical Management The Integrated Supply Chain Process. McGraw-Hill Companies Inc, New York.

Byrne, P. J. and Heavey, C. (2006), The impact of information sharing and forecasting in capacitated industrial supply chains: A case study, International Journal of Production Economics, 103 (1),pp. 420-437.

Cambra, J. and Polo, Y. (2008), Creating satisfaction in the demand-supply chain: the buyer's perspective, Supply Chain Management: An International Journal, 13 (3), pp. 211-224.

Carter, J. R., Ferrin, B. G. and Carter, C.R. (1995), The effect of less-than-truckload rates on the purchase order lot size decision, Transportation Journal, 34 (3), pp. 35-44.

Canever, M., Van Trijp, H. and Beers, G. (2008), The emergent demand chain management: key features and illustration from the beef business, Supply Chain Management: An International Journal, 13 (2), pp. 104-115.

Charan, P., Shankar, R. and Baisya, R.K. (2009), Modelling the barriers of supply chain performance measurement system implementation in the Indian automobile supply chain, International Journal of Logistics Systems and Management, 5 (6), pp. 614-630.

Chen J. (1997), Achieving maximum Supply chain efficiency, IIE Solutions, 29, pp. 30-35.

Christopher, M. (1998). Logistics and Supply Chain Management: Strategies for Reducing Costs and Improving Services (2nd ed.). Pitman, London

Christopher, M. and Gattorna, J. (2005), Supply chain cost management and value-based pricing, Industrial Marketing Management, 34 (2), pp. 115- 121.

Collin, F., Eloranta, E. and Holmström, J. (2009), How to design the right supply chains for your customers, Supply Chain Management: An International Journal, 14 (6), pp. 411-417.

de Waal, A.A. and Counet, H. (2009), Lessons learned from performance management systems implementations, International Journal of Productivity and Performance Management, 58 (4), pp. 367-390.

Ellram, L. and Cooper, M. (1990), Supply chain management, partnerships and the shipper - third party relationship, The International Journal of Logistics Management, 1 (2), pp. 1-10.

Fawcett, S. E., Magnan, G. M. and McCarter, M. W. (2008), Benefits, barriers, and bridges to effective supply chain management, Supply Chain Management: An International Journal, 13 (1), pp. 35-48.

Forslund, H. and Jonsson, P. (2007), Dyadic integration of the performance management process: A delivery service case study, International Journal of Physical Distribution \& Logistics Management, 37 (7), pp. 546 - 567.

Forslund, H. (2010), ERP systems' capabilities for supply chain performance management, Industrial Management Data Systems, 110 (3), pp. 351-367.

Halldorsson, A., Larson, P.D. and Poist, R.F. (2008), Supply chain management: a comparison of Scandinavian and American perspectives, International Journal of Physical Distribution \& Logistics Management, 38 (2), pp. 126-42.

Hatzis, A., Koulidou, A. and Folinas, D. (2011), Costing logistics services, Operations and Supply Chain Management, 4 (2/3), pp. $116-122$.

Hayashi, A., Ishii, N and Matsui, M. (2009), A theory and tools for collaborative Demand-to-Supply management in the SCM age, Operations and Supply Chain Management, 2 (2), pp. 111-124.

Higginson, J. K., Alam, A. (1997), Supply chain management techniques in medium-to-small manufacturing firms, International Journal of Logistics Management, 8 (2), pp. 1932.

Huan, S. H., Sheoran, S. K. and Wang, G (2004), A review and analysis of Supply chain operations reference (SCOR) model, Supply Chain Management: An International Journal, 9 (1), pp. 23-29.

Johnston, P. (1995), Supply chain management: past, the present and the future, The Manufacturing Engineer, pp. 213-217.

Krantz, S (1996), What is it?, Purchasing Today, October, pp. 4.

Kumar, S. and Chang, C.W. (2007), Reverse auctions: How much total supply chain cost savings are there? - A business simulation model, Journal of Revenue and Pricing Management, 6 (3), pp. 229-240.

Kähkönen, A-K. (2011), Conducting a Case Study in Supply Management. Operations \& Supply Chain Management, 4, (1), pp. 31-41.

Lahti, M., Shamsuzzoha, A.H.M. and Helo, P. (2009). Developing a maturity model for Supply Chain Management, International Journal of Logistics Systems and Management, 5 (6), pp. 654 678.

MacFarland, R., Bloodgood, J. and Payan, J. (2008), Supply chain contagion, Journal of Marketing, 72 (2), pp. 63-79.

Mondragon, A.E.C. and Lalwani, C. (2011), Measures for auditing performance and integration in closed-loop supply chains, Supply Chain Management: An International Journal, 16 (1), pp. 43-56.

New, S.J. (1996), A framework for analysing supply chain improvement, International Journal of Operations \& Production Management, 15 (4), pp. 19-34.

Pettersson, A. I. and Segerstedt, A. (2011), Performance measurements in supply chains within Swedish industry, International Journal of Logistics Systems and Management, 9 (1), pp. 69-88.

Pettersson, A. I. and Segerstedt, A. (2012), Measurements of excellence in a supply chain, International Journal of Logistics Systems and Management, 13 (1), pp. 65-80.

Pettersson, A. I. and Segerstedt, A. (2013), Measuring Supply Chain Cost, International Journal of Production Economics, 143 (2), pp. 357-363

Sachan, A., Sahay, B. S. and Sharma, D. (2005), Developing Indian grain Supply chain cost model: system dynamics approach, International Journal of Productivity and Performance Management, 54 (3), pp. 187-205

SCOR handbook version 8

Shahabuddin, S. (2011), Supply Chain Management and its effect on company's performance, International Journal of Logistics Systems and Management, 8 (1), pp. 101- 117.

Shapiro, J. F. (2001). Modeling the Supply Chain. Duxbury, Pacific Grove.

Simchi-Levy, D., Kaminsky, P. and Simchi-Levy, E. (2000) Designing and Managing the Supply Chain. McGraw-Hill, USA 
Spens, K and Wisner, J. (2009), A study of Supply Chain Management practices in Finland and the United States, Operations and Supply Chain Management, 2 (2), pp. 79-92

Svensson, G. (2010), Teleological approaches in supply chain management: illustrations, Supply Chain Management: An International Journal, 15 (1), pp. 16-20.

Tan, C.K., Lyman, S.B. and Wisner, J.D. (2002), Supply chain management: a strategic perspective, International Journal of Operations \& Production Management, 22 (6), pp. 614-631.
Walters, D. (2008), Demand chain management + response management $=$ increased customer satisfaction, International Journal of Physical Distribution \& Logistics Management, 38 (9), pp. 699-725.

Yin, R.K. (2003). Case study research: Design and methods. Sage Publications, Thousand Oaks, California.

Annelie I. Pettersson has an MSc in Mechanical Engineering and an MBA in Economics from Luleå University of Technology, Sweden. Since then, she has been working in industry and she is now a supply chain manager at the company Ericsson in Sweden. She has a Lic Tech in Industrial Logistics from Luleå University of Technology in 2008; her current research interest is supply chain excellence.

Anders Segerstedt received his MSc, Lic Tech, Dr Tech and Docent all from Linköping Institute of Technology; since 2004, he is a Professor in Industrial Logistics at Luleå University of Technology. He has worked as a senior lecture at Mälardalen University and Professor II at Narvik University College; he has also 16 years of experiences from different full-time positions in industry (1975-1991). 